\title{
Predicting castration-resistant prostate cancer after combined androgen blockade
}

\author{
Miao He ${ }^{1}$, Haina Liu ${ }^{1}$, Jingyi Cao ${ }^{2}$, Qian Wang ${ }^{2}$, Haiting $\mathrm{Xu}^{3}$ and Yufeng Wang ${ }^{1}$ \\ ${ }^{1}$ Department of Nuclear Medicine, Xuzhou Cancer Hospital, Jiangsu Province, Xuzhou, China \\ ${ }^{2}$ Department of Urology, Xuzhou Cancer Hospital, Jiangsu Province, Xuzhou, China \\ ${ }^{3}$ Department of Radiotherapy and Oncology, Xuzhou Cancer Hospital, Jiangsu Province, Xuzhou, China \\ Correspondence to: Yufeng Wang, email: wangyufengxz@163.com \\ Keywords: prostate cancer; bone metastasis; bone scan; combined androgen blockade; castration resistance \\ Received: March 24, $2017 \quad$ Accepted: October 02, $2017 \quad$ Published: November 01, 2017 \\ Copyright: He et al. This is an open-access article distributed under the terms of the Creative Commons Attribution License 3.0 \\ (CC BY 3.0), which permits unrestricted use, distribution, and reproduction in any medium, provided the original author and source \\ are credited.
}

\section{ABSTRACT}

This study analyzed ${ }^{99} \mathrm{Tcm}-\mathrm{MDP}$ bone scans and investigated factors influencing early-stage castration resistance in prostate cancer (CRPC) patients with bone metastasis. We retrospectively analyzed clinical data from 92 patients with bone metastatic prostate cancer treated with maximal androgen blockade. Patients were imaged with ${ }^{99} \mathrm{Tcm}-\mathrm{MDP}$ bone scan to detect metastases, and prostate specific antigen (PSA) values were measured regularly. Before treatment, 464 total bone metastases were detected in the 92 patients, with pelvic bone metastases accounting for about $30.6 \%$ of the total. After combined androgen blockade treatment, median CRPC occurrence time was $\mathbf{2 3}$ months. A longer time to reach the lowest PSA value was an independent predictor of early-onset CRPC (occurrence $<1$ year after treatment). Our findings suggest that ${ }^{99} \mathrm{Tcm}-\mathrm{MDP}$ bone scans are useful for diagnosing prostate cancer bone metastasis and grading. Patients with Gleason scores $>8$, higher PSA values after treatment, and shorter times to reach the lowest PSA value had poorer responses to combined androgen blockade treatment.

\section{INTRODUCTION}

Prostate cancer incidence differs depending on geographical location and patient ethnicity. In Europe, the United States, and other developed nations, prostate cancer is the most common malignancy in males [1]. While prostate cancer incidence is lower in Asian than Western countries, prostate cancer has become increasingly common in Asia. Prostate cancer is now the third most common malignancy of the male urinary tract and reproductive system in China, seriously affecting quality of life in elderly men.

More than $90 \%$ of prostate cancer patients will eventually have bone metastases. Early diagnosis of prostate cancer with or without bone metastases, and accurate assessment of bone metastasis locations and quantities are very important for therapeutic decisionmaking. ${ }^{99} \mathrm{Tcm}-\mathrm{MDP}$ is a noninvasive, highly sensitive radiotracer commonly used to screen for malignant tumors with or without bone metastases. 99Tcm-MDP is frequently used to diagnose prostate cancer patient bone metastases and to evaluate therapeutic efficacies [2].

Prostate cancer with bone metastases is an advanced stage disease with considerably poorer prognosis. Combined androgen blockade therapy is often the preferred treatment for these patients [3]. We followed-up patients whose bone metastases were imaged via singlephoton emission computerized tomography (SPECT), and found that nearly all of these patients experienced disease progression and developed castration resistant prostate cancer (CRPC) [4]. More accurate clinical indicators and biomarkers are needed to inform personalized treatment options for patients with CRPC.

This study retrospectively analyzed prostate cancer patient data to identify prostate cancer bone metastasis clinical features and evaluate the effectiveness of 
Table 1: Distribution of bone metastases

\begin{tabular}{lc}
\hline Site & Number of bone metastases $(\%)$ \\
\hline Pelvis & $142(30.6 \%)$ \\
Spine & $110(23.7 \%)$ \\
Ribs & $89(19.2 \%)$ \\
Limb bones & $58(12.5 \%)$ \\
Sternum & $36(7.8 \%)$ \\
Skull & $16(3.4 \%)$ \\
Others & $13(2.8 \%)$ \\
\hline
\end{tabular}

combined androgen blockade therapy in patients with bone metastases. We assessed strategies for early identification of patients with bone metastases insensitive to combined androgen blockade therapy, and explored personalized treatment regimens for metastatic prostate cancer.

\section{RESULTS}

In this study, 92 prostate cancer cases were diagnosed with bone metastases and were ${ }^{99} \mathrm{Tcm}-\mathrm{MDP}$ bone scan positive. According to the Soloway grading criteria, 36/92 prostate cancer cases were diagnosed via ${ }^{99} \mathrm{Tcm}-\mathrm{MDP}$ bone scans as grade I, 24/92 as grade II, and $32 / 92$ as grade III. The total number of bone metastases diagnosed using ${ }^{99} \mathrm{Tcm}-\mathrm{MDP}$ was 464 , with $30.6 \%$ found in the pelvic bone, $23.7 \%$ in the spine, $19.2 \%$ in ribs, and $12.5 \%$ in limbs (most commonly in the proximal femur) (Table 1).

All 92 patients with bone metastases underwent anti-androgen therapy after initial SPECT bone scan, and were followed up regularly using bone scans and serum prostate specific antigen (PSA) measurements. Patient clinical characteristics are shown in Table 2. Receiver operating characteristic curve analysis (ROC) was used to determine whether the lowest PSA values and the time to reach the minimal PSA value could be used to predict CRPC. The results showed that the optimal cutoff value of the lowest PSA values and the time to reach the minimal PSA value for predicting CRPC were $0.2 \mathrm{ng} / \mathrm{mL}$ and 9 months, respectively. CRPC was diagnosed in 51 patients during the follow-up period. Early CRPR (development within one year of treatment) was diagnosed in 24 patients (47\%). Mean time to CRPC was 23 months. Patients were grouped according to clinical indicators, and chi-square test results showed that patients with Gleason scores (8-10vs. 6-7) had the lowest PSA values after combined androgen blockade therapy, and the time to reach the minimal PSA value was associated with CRPC development after treatment (Table 2).

According to non-parametric and chi-square analyses, early-onset CRPC patients had the highest PSA values, and the longest times to reach the lowest PSA values (Table 3). Logistic regression analysis showed that time to lowest PSA value was an independent predictor of early-onset CRPC (Table 4). We found that PSA value decline patterns in patients who underwent combined androgen blockade therapy could indicate CRPC occurrence. CRPC developed earliest in patients with the highest PSA values $(\geq 0.2 \mathrm{ng} / \mathrm{mL})$ and the longest times to the lowestPSA values (Table 3 ).

\section{DISCUSSION}

Metastasis to the bone is a common problem in prostate cancer. Tumor cells reach bone sites mainly via inferior vena cava blood reflux, followed by arterial flow to the body, through the deep vein of the penis to the Batson vertebral venous plexus, finally reaching the pelvis and lumbar vertebrae $[5,6]$. Batson suggested that there is a "portal-like" vein system between the prostate and the low lumbar spine, leading to increased risk of prostate cancer metastasis to the spine. Prostate cancer can also metastasize to the pelvis [7, 8]. In this study, 464 bone metastatic lesions were diagnosed via ${ }^{99} \mathrm{Tcm}-\mathrm{MDP}$ bone scan, the majority of which were found in the pelvic bone $(30.6 \%)$ or spine $(23.7 \%)$.

The most commonly used first-line clinical treatment for prostate cancer patients with bone metastases is combined androgen blockade, which is more efficacious than castration or anti-androgen therapy alone [9]. However, almost all patients experience disease progression (CRPC) at some point after initial treatment. For those patients insensitive to combined androgen blockade treatment, more sensitive predictors of disease progression will allow for better therapeutic decisionmaking and patient outcomes. In this retrospective study, we found that Gleason scores and PSA changes after combined androgen blockade therapy were associated with treatment outcomes. Patients with high Gleason scores, high minimum PSA values, and short times to reach minimum PSA values after treatment developed CRPC earlier than other patients, and these factors independently predicted early-onset CRPC. 
Table 2: Relationships between clinicopathological characteristics and CRPC in patients with prostate cancer

\begin{tabular}{|c|c|c|c|c|}
\hline Characteristics & Group & $\begin{array}{c}\text { Total number of } \\
\text { patients }\end{array}$ & $\begin{array}{c}\text { Number of } \\
\text { patients with } \\
\text { CRPC }\end{array}$ & $P$-value \\
\hline \multirow[t]{2}{*}{ Age } & $\leq 75$ & 50 & 31 & 0.21 \\
\hline & $>75$ & 42 & 20 & \\
\hline \multirow[t]{2}{*}{ Preoperative PSA (ng/mL) } & $\leq 100$ & 45 & 22 & 0.21 \\
\hline & $>100$ & 47 & 29 & \\
\hline \multirow[t]{2}{*}{ Gleason score } & $<8$ & 67 & 30 & $<0.01$ \\
\hline & $\geq 8$ & 25 & 21 & \\
\hline \multirow[t]{2}{*}{ Number of bone metastases } & $\leq 4$ & 43 & 23 & 0.83 \\
\hline & $>4$ & 49 & 28 & \\
\hline \multirow{2}{*}{$\begin{array}{l}\text { Lowest value of PSA after maximal } \\
\text { androgen blockade therapy (ng/ } \\
\mathrm{mL} \text { ) }\end{array}$} & $\leq 0.2$ & 50 & 14 & $<0.01$ \\
\hline & $>0.2$ & 42 & 37 & \\
\hline \multirow{2}{*}{$\begin{array}{l}\text { Time to reach minimal PSA } \\
\text { (months) }\end{array}$} & $\leq 9$ & 52 & 36 & $<0.01$ \\
\hline & $>9$ & 40 & 15 & \\
\hline
\end{tabular}

Table 3: Relationships between clinicopathological characteristics and CRPC in patients with prostate cancer after one year of treatment

\begin{tabular}{|c|c|c|c|c|}
\hline \multirow[t]{2}{*}{ Variable } & \multicolumn{3}{|c|}{ Median time to CRPC } & \multirow[t]{2}{*}{$P$-value } \\
\hline & & $\geq 1$ year & $<1$ year & \\
\hline Preoperative PSA (ng/mL) & & 109 & 123 & 0.27 \\
\hline \multirow[t]{2}{*}{ Gleason score } & $<8$ & 19 & 13 & 0.26 \\
\hline & $\geq 8$ & 8 & 11 & \\
\hline \multirow[t]{2}{*}{ Number of bone metastases } & $\leq 4$ & 15 & 10 & 0.40 \\
\hline & $>4$ & 12 & 14 & \\
\hline $\begin{array}{l}\text { Lowest PSA value after maximal } \\
\text { androgen blockade therapy (ng/ } \\
\mathrm{mL} \text { ) }\end{array}$ & & 0.4 & 1.92 & $<0.01$ \\
\hline $\begin{array}{l}\text { Time to reach minimal PSA } \\
\text { (months) }\end{array}$ & & 8.5 & 3.9 & $<0.01$ \\
\hline
\end{tabular}

Gleason score is an important parameter in prostate cancer grading. High Gleason scores represent high tumor heterogeneity and poor tumor cell differentiation, indicating loss of glandular structure. Our study showed that prostate cancer patients with Gleason scores of 8-10 had were at higher risk for CRPC occurrence after maximal androgen blockade. Combined androgen blockade treatment was not efficacious in these patients, and early combined treatment should be considered.

Measurement of PSA in serum is an excellent method for early detection and diagnosis of prostate cancer [10]. At present, PSA is the first line method for prostate cancer monitoring $[11,12]$. Our study showed that there was no relationship between PSA level before combined androgen blockade treatment and time to CRPC after treatment $(\mathrm{P}>0.05)$, although changes in PSA were directly associated with time to CRPC. Patients with the lowest PSA values developed CRPC later than other patients, and this was a good marker for combined androgen blockade treatment efficacy. Combined androgen blockade reduced PSA values in most patients by more than $80 \%$ in the first month [13]. However, some studies had shown that PSA decline did not indicate tumor cell death, but instead represented AR pathway inhibition 
Table 4: Multivariate analysis in patients with bone metastases who underwent anti-androgen therapy for CRPC after one year of initial treatment

\begin{tabular}{lcccc}
\hline Variable & Group & HR & 95\% CI & P-value \\
\hline Lowest PSA value after maximal & $\leq 0.2$ & 1 & & \\
androgen blockade therapy & $>0.2$ & 21.6 & $6.4-73.0$ & $<0.01$ \\
Time to reach minimal PSA (months) & $\leq 9$ & 1 & 0.2 & $0.1-0.7$ \\
\hline
\end{tabular}

HR: hazard ratio; CI: confidence interval.

and subsequent reduced PSA secretion [14]. However, a slower PSA reduction following an initial rapid decline is considered representative of tumor load reduction. Thus, we analyzed the relationship between the time to PSA minimum value and CRPC incidence post-treatment. Our findings suggested that CRPC occurred later in patients whose PSA measurements reached minimum values $>9$ months post-treatment. Sasaki, et al. and Hussain, et al. similarly concluded that patients with longer times to minimum PSA values had longer overall survival times than those with shorter times to minimal PSA [15].

In summary, prostate cancer is highly susceptible to bone metastases. We found that patients with Gleason scores $>8$, PSA minimum values $>0.2 \mathrm{ng} / \mathrm{mL}$, and times to minimum PSA value $<9$ months had poor responses to maximal androgen blockade treatment. Therefore, early combined treatment should be considered in these patients.

\section{MATERIALS AND METHODS}

\section{Subjects}

This study retrospectively analyzed clinical data from 92 cases of prostate cancer with bone metastasis treated usingcastration combined with oral anti-androgen therapy between 2010 and 2015 at the Xuzhou Tumor Hospital. All patients underwent routine bone scans, rectal prostate ultrasound, PSA and free PSA assessments, and prostate biopsy before treatment to confirm the diagnosis of prostate cancer with bone metastasis. After castration surgery, patients began anti-androgen therapy with either bicalutamide or flutamide, and regular outpatient followup bone scans and PSA measurements were performed.

The 2014 European Union Urological Association guidelines define CRPC biochemically as three consecutive PSA increases (each one week apart), two PSA measurements $>50 \%$ above the lowest value, and PSA $>2$ $\mathrm{ng} / \mathrm{mL}$. Early CRPC was defined as CRPC occurring within one year of combined androgen blockade therapy.

\section{Statistical analysis}

Statistical analyses were performed using SPSS 16.0 software. $\mathrm{P}<0.05$ was considered statistically significant.
Nonparametric and chi-square tests were used to compare differencesbetween early CRPC and other CRPC patients. Logistic regression was used to analyze independent factors associated withearly CRPC.

\section{CONFLICTS OF INTEREST}

The authors declare that they have no conflicts of interest.

\section{REFERENCES}

1. Siegel RL, Miller KD, Jemal A. Cancer statistics, 2016. CA Cancer J Clin. 2016; 66:7-30.

2. Thompson I, Thrasher JB, Aus G, Burnett AL, CanbyHagino ED, Cookson MS, D'Amico AV, Dmochowski RR, Eton DT, Forman JD, Goldenberg SL, Hernandez J, Higano $\mathrm{CS}$, et al. Guideline for the management of clinically localized prostate cancer: 2007 update. J Urol. 2007; 177:2106-2131.

3. Seidenfeld J, Samson DJ, Hasselblad V, Aronson N, Albertsen PC, Bennett CL, Wilt TJ. Single-therapy androgen suppression in men with advanced prostate cancer: a systematic review and meta-analysis. Ann Intern Med. 2000; 132:566-577.

4. McLoughlin LC, O'Kelly F, O'Brien C, Sheikh M, Feeney J, Torreggiani W, Thornhill JA. The improved accuracy of planar bone scintigraphy by adding single photon emission computed tomography (SPECT-CT) to detect skeletal metastases from prostate cancer. Ir J Med Sci. 2016; 185:101-105.

5. Chen YH, Nie P, Jiang W, Zhao SJ, Zhang Z, Lin HX, Li MY, Liu YQ, Li PH, Zhu XS. [Predictive factors for bone metastases of prostate cancer]. [Article in Chinese]. Nan Fang Yi Ke Da Xue Xue Bao. 2016; 36:205-209.

6. Gravina GL, Mancini A, Muzi P, Ventura L, Biordi L, Ricevuto E, Pompili S, Mattei C, Di Cesare E, Jannini EA, Festuccia C. CXCR4 pharmacogical inhibition reduces bone and soft tissue metastatic burden by affecting tumor growth and tumorigenic potential in prostate cancer preclinical models. Prostate. 2015; 75:1227-1246. 
7. Cheville JC, Tindall D, Boelter C, Jenkins R, Lohse CM, Pankratz VS, Sebo TJ, Davis B, Blute ML. Metastatic prostate carcinoma to bone: clinical and pathologic features associated with cancer-specific survival. Cancer. 2002; 95:1028-1036.

8. Van Loon K, Zhang L, Keiser J, Carrasco C, Glass K, Ramirez MT, Bobiak S, Nakakura EK, Venook AP, Shah $\mathrm{MH}$, Bergsland EK. Bone metastases and skeletal-related events from neuroendocrine tumors. Endocr Connect. 2015; 4:9-17.

9. Amato R, Stepankiw M, Gonzales P. A phase II trial of androgen deprivation therapy (ADT) plus chemotherapy as initial treatment for local failures or advanced prostate cancer. Cancer Chemother Pharmacol. 2013; 71:1629-1634.

10. Smith MR, Cook R, Lee KA, Nelson JB. Disease and host characteristics as predictors of time to first bone metastasis and death in men with progressive castrationresistant nonmetastatic prostate cancer. Cancer. 2011; 117:2077-2085.

11. Greene KL, Albertsen PC, Babaian RJ, Carter HB, Gann PH, Han M, Kuban DA, Sartor AO, Stanford JL, Zietman A,
Carroll P. Prostate specific antigen best practice statement: 2009 update. J Urol. 2013; 189:S2-S11.

12. Koo KC, Park SU, Kim KH, Rha KH, Hong SJ, Yang SC, Chung BH. Predictors of survival in prostate cancer patients with bone metastasis and extremely high prostate-specific antigen levels. Prostate Int. 2015; 3:10-15.

13. Arai Y, Yoshiki T, Yoshida O. Prognostic significance of prostate specific antigen in endocrine treatment for prostatic cancer. J Urol. 1990; 144:1415-1419.

14. Wenisch JM, Mayr FB, Spiel AO, Radicioni M, Jilma B, Jilma-Stohlawetz P. Androgen deprivation decreases prostate specific antigen in the absence of tumor: implications for interpretation of PSA results. Clin Chem Lab Med. 2014; 52:431-436.

15. Sasaki T, Onishi T, Hoshina A. Nadir PSA level and time to PSA nadir following primary androgen deprivation therapy are the early survival predictors for prostate cancer patients with bone metastasis. Prostate Cancer Prostatic Dis. 2011; 14:248-252. 